\title{
The use of unfolding case studies: I nnovation in online undergraduate nursing education
}

\author{
Yvonne K. Yousey \\ School of Nursing, University of Northern Colorado, Greeley, USA \\ Correspondence: Yvonne K Yousey. Address: School of Nursing, University of Northern Colorado, Gunter Hall, Box 125, \\ Greeley, CO 80639, USA. Email: Yvonne.Yousey@unco.edu.
}

Received: July 13, 2012

Accepted: September 12, 2012 Online Published: December 4, 2012

DOI : 10.5430/jnep.v3n4p21

URL: http://dx.doi.org/10.5430/jnep.v3n4p21

\begin{abstract}
Background: Educational strategies are needed to prepare nurses to become sophisticated consumers of information and to apply that information in practice. Expertise in problem solving and clinic decision making skills is necessary if nurses are to function effectively in an increasingly complex health care environment. RNs entering programs leading to bachelor degrees (RN-BSN) have basic skills but need opportunity to develop higher level creative problem solving and critical thinking skills. The purpose of this article is to investigate the use of the "unfolding case study" as an innovative strategy to increase clinical decision making and problem solving skills in participants in a public health course in an online nursing program.
\end{abstract}

Methods: Participants in a public health nursing course were assigned to develop a case study over time integrating concepts of chronic illness with public health nursing. This problem based learning method supported adult learning principles of motivation, autonomous learning, and application to practice, all elements of online learning. The unfolding case studies were evaluated using a rubric to insure that participants completed course objectives. A survey, administered at the end of the course, provided feedback on perceptions of learning using this strategy.

Results: All students successfully completed the unfolding case study over a four week period through which they demonstrated integration of knowledge and application in the clinical setting. Feedback provided by participants confirmed an increase in knowledge of public health nursing, creative problem solving, and the ability to apply concepts of chronic illness using a public health framework.

Conclusions: The "unfolding case study" in this public health nursing course served as a means of increasing nurses' knowledge, complex critical thinking and problem solving skills in an online program for RN-BSN participants. While participants presented initially with a wide range of abilities in problem solving and clinical decision making, they demonstrated an increase in problem solving, awareness and application to practice through the use of the unfolding case study.

\section{Key words}

Online learning, Problem based learning, Unfolding case studies 


\section{Introduction}

Registered nurses (RNs) need well developed problem-solving and critical thinking skills to address the challenges of providing nursing care in increasingly complex health care settings ${ }^{[1]}$. They need to be sophisticated consumers of information, and have the ability to utilize quality clinical decision making skills in clinical practice. RNs entering programs leading to bachelor degrees (RN-BSN) have basic skills, but need opportunity to develop higher level creative problem solving and critical thinking skills ${ }^{[2]}$. These skills include the ability to design nursing care, interpret practice situations and use their judgment to provide sensitive and timely care ${ }^{[3]}$. Strategies that facilitate the development of these skills are needed in nursing education.

The recent proliferation of online nursing programs targeting $\mathrm{RN}$ participants presents new challenges in implementing innovative strategies that facilitate problem solving and critical thinking skills. Methods previously used effectively in face-to-face classes may not be applicable in online learning ${ }^{[4]}$. Online programs must foster growth in cognitive, behavioral, and social areas, with little opportunity for face-to-face interaction between participants and faculty ${ }^{[2]}$. Technology is needed that will create an interactive assessment for students allowing them to face real-world situations and demonstrate that they understand the concepts being taught ${ }^{[4]}$. The use of "unfolding case studies" is an innovative problem-based online learning strategy that meets these challenges.

This article will present an example of the use of the "unfolding case study" as an innovative strategy to increase clinical decision making and problem solving skills through participation in a public health course in an online nursing program. The ability of RN participants to design nursing care, interpret practice situations, and develop the complex cognitive process of problem solving within this assignment is described.

\section{Framework}

The "unfolding case study" as an innovative strategy engages the learner through the intentional development of a story that directs learning and integration of knowledge ${ }^{[5]}$. It includes a written depiction (story) of problem-oriented events occurring over time, requiring that learners be actively engaged in solving clinical problems by applying knowledge, independent thinking skills, and critical thinking ${ }^{[6]}$. The "unfolding case study" goes one step further than the traditional case study in varying the presentation and order of content ${ }^{[7]}$, requiring the learner to make inferences and decisions before all information is available and to recognize that problems may have more than one correct answer ${ }^{[8]}$. This simulates clinical, real-world settings ${ }^{[9,10]}$ and requires thoughtful assessment in facilitating safe and competent nursing practice. The effectiveness of the unfolding case study has been demonstrated in classroom settings and in simulation scenarios ${ }^{[7]}$ and now is being initiated in online education.

Kim et al. ${ }^{[9]}$ developed a framework for implementation of the unfolding case study that focuses on content, structure, and process, and can be used in a variety of learning settings including the online environment. Integrated in the framework are the five attributes--relevance, realism, challenge, engagement, and instruction (see Table 1). It connects theory and practice by providing learning strategies that facilitate skills of problem solving and clinical decision making in the practice setting.

In the learning activity discussed here, principles of public health nursing and chronic illness are applied and integrated. The development of content is guided by the attributes of relevance to the illness being studied, realism based on real life experiences, engagement of the learner, and the challenge of learning. Structure in the framework focuses on how information is organized and shared, and process addresses assessing prior knowledge of the learners, role of the instructor, and use of teaching aids ${ }^{[9]}$. Concepts of chronic illness including the meaning of and adaptation to chronic illness, social isolation, caregiver issues, quality of life issues during transitions in chronic illness, and case management ${ }^{[11]}$ are integrated with public health principles such as population-based health, epidemiology, primary, secondary, 
and tertiary prevention ${ }^{[12]}$. Guided by the attributes in the framework and concepts of chronic illness and public health, nursing judgment and clinical decision making are integrated into the plans for clients and families rather than simply applying rules and principles prescriptively ${ }^{[13]}$.

Table 1. Attributes of the Unfolding Case Study

\begin{tabular}{|c|c|}
\hline Attributes & Description \\
\hline Relevance & $\begin{array}{l}\text { Meets goals and objectives of the course. } \\
\text { Content is appropriately leveled for learner. }\end{array}$ \\
\hline Realistic & $\begin{array}{l}\text { Case study story is disclosed in stages over time. } \\
\text { Detractors including irrelevant information and missing relevant information are included to simulate real } \\
\text { life assessment. }\end{array}$ \\
\hline Engaging & $\begin{array}{l}\text { Information is provided using multiple perspectives and concepts. } \\
\text { Rich content includes information on people, places, problems, situations and tasks associated with } \\
\text { chronic illness. } \\
\text { Opportunity for learner to determine a variety of outcomes of case through decision making. }\end{array}$ \\
\hline $\begin{array}{l}\text { Challenging } \\
\text { Instructional }\end{array}$ & $\begin{array}{l}\text { Varying levels of difficulty appropriate for learners. } \\
\text { Unusual components are included to increase challenge. } \\
\text { Complexity of information requiring analysis of options for treatment and management. } \\
\text { Providing information using both chronological and non-chronological methods to increase complexity } \\
\text { in clinical decision making. } \\
\text { Build and increase knowledge. } \\
\text { Means for assessing knowledge level and ability of students to apply information. } \\
\text { Teaching aids. } \\
\text { Feedback during process }\end{array}$ \\
\hline
\end{tabular}

\section{I mplementation}

The unfolding case study was implemented in a public health nursing course in an online RN-BSN program in a School of Nursing with the goal of expanding the participants' abilities in integrating knowledge, in clinical decision making, and problem solving. RN participants actually developed the case study, with a focus on chronic illness instead of completing one that was already developed. They integrated public health concepts with chronic illness in assessing, planning, implementing, and managing care of clients and families, consistent with baccalaureate nursing education ${ }^{[14]}$.

Even though the assignment was part of a course, IRB approval was obtained in order to query the participants about the experience. Participants included twenty-six students in an RN-BSN online nursing program. The public health nursing course was the final course in the curriculum, which allowed participants to synthesize concepts from the entire program as well as from the course.

All participants completed the course assignment, at the end of which they were invited to evaluate the assignment through a survey. They provided informed consent for the participation in the project by completing the survey. For the purposes of clarity in the following discussion, RN participant refers to the student developing the case study and the learner refers to the hypothetical student who would utilize the unfolding case study for learning.

The assignment was organized using a hypothetical scenario in which participants were supervisors in a home health agency. They were to educate new nurse employees in the care of clients with chronic illness in a community setting using an unfolding case study. The level of the learner (RN with no public health experience) and the setting for the case study 
(home health agency and associated settings) were consistent for all participants. Participants could select a chronic illness based on their interest and experience and then build the case study around that illness guided by unit objectives and readings assigned for the course. The participants developed the case study in three stages, over a four week period following attributes identified in the framework (see Table 1). A template that outlined necessary steps in each stage and previously completed unfolding case studies were provided as examples to clarify the process. Because the assignment was completed by each participant working independently, there was no peer interaction or feedback. Participants were able to obtain faculty feedback and the opportunity to revise the case during the four week time frame.

To begin the unfolding case study, the participant developed a plan for assessing the knowledge of the learner. Following the completion of a literature review of evidence based practice of the chronic illness, goals and objectives for learning were developed. Each participant then introduced the chronic illness through the "story" of a client which included clinical manifestations of the disease, chronic illness trajectory, nursing assessment and interventions based on clinical symptoms. The setting of the case study, based in a home health agency could also include a hospital or other health care facility, community, and client's home as guided by the public health framework ${ }^{[12]}$.

In the second stage, the participant expanded the context include activities in more than one setting, complications of the illness, family coping, access to resources, health system issues, financial issues, and availability and use of community resources. Nursing assessment and planning care in this stage focused on chronic illness concepts that encouraged the learner to address the impact of illness on the family, cultural aspects of care, adherence, powerlessness, alternative and complimentary therapies ${ }^{[11]}$.

Health promotion and/or disease prevention strategies were included with families depending on the chronic illness being investigated ${ }^{[14]}$. As participants further developed the story, they included both relevant and irrelevant information, and left out elements of information that might be needed in decision making to emulate real life situations with changing circumstances and decisions that need to be made before all information is available. Information was presented in such a way that the learner could integrate knowledge of effective, evidence based treatments, family coping, values and beliefs of the family, health system options and community resources in the planning of care ${ }^{[11]}$.

Learning strategies in the second stage included the development of questions by participants to guide learning. Based on the essentials of baccalaureate nursing ${ }^{[14]}$, the participants had to understand signs and symptoms, treatment, and management of chronic illness before they could develop questions that required analysis and problem solving. To insure that they were meeting learning outcomes for the course, participants identified which unit objectives the questions in each stage addressed. Consistent with learning strategies for adult learners, this encouraged participants to focus on the areas that were relevant to the case study and of greatest interest to them.

In the last and final stage, participants completed the story leading to complete recovery, recovery with disability, or death, representing the three levels of intervention—-primary, secondary and tertiary ${ }^{[12]}$. They integrated trajectory of the chronic illness for the family with use of community resources. In this stage, they considered possible ethical issues that might arise and summarized the outcome based on their unfolding story. Finally, they answered the questions that they had posed for the learner in all stages, providing evidence of their own knowledge and application in a "real life setting". Answers were supported by references. As they answered the questions, they were able to "tweak" parts of the story to make it more relevant, realistic, challenging, or to alter questions to further facilitate learning.

A discussion board with guided questions addressing understanding and application of course content and readings was a required part of a concurrent clinical course for participants. This provided opportunity to reflect and monitor their metacognition through sharing their learning with one another. Faculty monitored the participants' discussion and provided feedback. The discussion was evaluated on a satisfactory/unsatisfactory basis, consistent with the course in which it was included. 


\section{Example of implementation}

One participant completed a case study on breast cancer, focusing on a female client and her family as they experienced the diagnosis and treatment beginning in the hospital and moving to the client's home. The story included perspectives of the client, the client's family including teen-age children, the case manager, and physician in the planning and management of care. The first stage focused on assessment and plan of care that included aspects of the chronic illness, disease management, treatment, and education of the family. The participant developed the case study demonstrating how the client and family moved through the various settings and stages of treatment. As this occurred, population focus of care was introduced through investigation of community resources and epidemiology of the disease process ${ }^{[12]}$. Questions that were developed by the participant to guide learning in the first stage focused on the client and family understanding of breast cancer as a chronic disease and expectations related to surgery and post surgery treatment. These addressed the unit objective requiring identification of interventions that facilitate family management of chronic illness and successful transitions for the whole family.

In the second stage, content expanded to include complications of the illness, increased need for family involvement, family coping with the chronic illness, access to resources, health care system issues, finances, and community resources. The client endured chemotherapy and radiation, only to discover that the treatments had not been effective, and there was evidence of metastasis. Not all costs of treatment were covered by insurance creating a financial burden for the family, resulting in lack of funds to allow teen-age children's participation in sports activities at school. The family considered alternative cancer therapy, not covered by insurance involving treatment in Mexico, travel and a six-week stay. The teen-agers became impatient, resentful and wanted family life to return to normal. Successful problem solving and planning of care in this stage required integration of knowledge of effective, evidence based treatments for cancer, family coping, values and beliefs of the family, health system options and community resources ${ }^{[11]}$. Questions in this stage focused on investigation of resources to address financial issues, knowledge of alternative therapies, and adjustment to changes in prognosis of the illness. In order to answer these, an understanding of the process of assisting clients and families with obtaining necessary resources, the advocacy roles of nurses in managing chronic illness, and knowledge of community resources for specific chronic conditions was necessary ${ }^{[14]}$.

Ethical issues arose when the client requested genetic testing, also not covered by insurance, to determine if teen-age daughters had the markers for cancer even though the reliability and validity of these tests had not yet been established. In order to solve this ethical issue, knowledge of sensitivity and specificity of screening tests was necessary and once determined then knowledge of community resources available was needed to solve the problem. The gravity of the prognosis in the final stage raised the question of when hospice services should be initiated. Clinical decision making and problem solving regarding family coping and the family's response to the grieving process, continuing financial issues, and coordination of community resources were necessary in this stage. The third and final stage included consideration of the ethical issues, preparation of the family for inevitable death of the patient, grieving and coping issues based on development of the family.

\section{Evaluation}

The conceptual framework ${ }^{[9]}$, essentials of baccalaureate education ${ }^{[14]}$, course and unit objectives provided the basis for formative and summative evaluation of the unfolding case study as an innovative strategy. The process supported individualized learning for participants as they progressed at their own rate and received regular, thoughtful, and prompt feedback as requested from faculty. As concepts of chronic illness were introduced and threaded throughout the module, participants were expected to integrate these in the problem solving scenarios in the unfolding case study.

The rubric for grading the unfolding case studies was built on identification of community health concepts ${ }^{[11]}$ and chronic illness ${ }^{[12]}$. Consistent with undergraduate baccalaureate education ${ }^{[14]}$ and with the framework ${ }^{[9]}$, it focused on integration and application of clinical knowledge in problem solving in a logical and organized manner. 
Table 2. Rubric for Evaluating Unfolding Case Studies

\begin{tabular}{ll}
\hline Activities to Meet Course Objectives & Points \\
\hline Case study is realistic, community based and focused on nurse-client-family interactions & 10 \\
Case study performance objectives are inclusive of content to be covered, explicit, and measurable & 10 \\
Case study questions meet or exceed 50\% of chronic illness course content learning objectives & 40 \\
Case study questions vary in style and require more than simple recall answers & 5 \\
Suggested answers to the case study questions are thorough, accurate, and verifiable. & 30 \\
$\begin{array}{l}\text { Case study demonstrates organization, accurate spelling, readability, } \\
\text { and provides references } \\
\text { Total Points }\end{array}$ & 5 \\
\hline
\end{tabular}

As a method of further assessing the participants' abilities in problem solving, awareness of their own metacognition and growth during this course, a fourteen item survey was administered through the online platform following the completion of the course (see Table 3). The participants answered the short answer questions related to their learning experience. Although not all participants completed the survey, it provided important information regarding perceptions of learning, changes in problem solving, and use of the framework for case study development.

Table 3. Evaluation of Learning

\section{Survey Questions}

What does "addressing chronic illness using a public health framework in nursing practice" mean to you?

What is the most important thing that you learned in the chronic illness unit of your Public Health Nursing course?

What did you like about completing the unfolding case study as an assignment for this unit?

What could have been done differently with this assignment to make it better?

What did you like about completing the discussion board reflections associated with the chronic illness units?

How will you use what you have learned in the chronic illness units in your nursing practice?

How will you use what you have learned about Public Health Nursing in this course in your future practice?

What else would you like to share about your participation as a student in the Public Health Nursing course?

\section{Results}

The use of a rubric based on course objectives and survey feedback provided data from two sources to ascertain the effectiveness of the unfolding case study as an innovative learning strategy. Each case study was graded using the following rubric based on course objectives (see Table 3). All students successfully completed the unfolding case study.

The participants provided the following feedback in answering the survey. In completing the question addressing chronic illness using a public health framework in nursing practice, participants identified "population focus", availability and use of community resources in solving problems of chronic illness, chronic illness prevention, comprehensive case management, holistic healing, and making decisions based on "greatest good for the greatest number" in developing the unfolding case studies. 
Participants identified an increase in knowledge of community resources, health promotion and preventions, and working with families in the community setting as the most important facets of their learning in response to the second question. Their response to what they liked included the opportunity to be creative and to think critically in completing the story-building process. Developing questions based on course objectives to guide their learning and the opportunity to work independently were also positive aspects.

When asked what could have been done differently in the assignment, participants requested more guidelines and structure as they moved through the process of completing the case study. They were challenged in following the steps and had difficulty in visualizing how the various steps of the process contributed to the whole. All but one participant found the use of the guided discussion questions in the concurrent clinical course to be of little or no value. Two participants noted that the discussion questions helped them summarize and consider their accomplishments in the course.

In response to the survey questions regarding what they learned about chronic illness and public health nursing, participants listed an increase in knowledge about community resources, health promotion and prevention, working with families and patient advocacy. Participants integrated the answers to these two questions even though the questions were asked separately. Their understanding of the role of the nurse in public health settings was broadened and three participants shared plans to move into public health roles in their career, either as employees or volunteers. Other participants noted that they focused on managing chronic illness, rather than on how the public health framework guided their activities.

In response to the final question, participants noted that regular, supportive monitoring of the case study process by faculty facilitated learning and the focus on individual learning was helpful. They also identified being able to integrate specifics of chronic illness with public health competencies as a result of completing the unfolding case study. There were no comments from participants suggesting that the discussion increased their ability to translate information into practice. One participant identified that completing the case study required work of the participants that "should be done by instructors”.

\section{Discussion}

The evaluation of the case study assignment based on course objectives augmented by the feedback from participants supported the use of this strategy as an effective method of learning in the online environment. By completing the assignment in stages, participants demonstrated their ability to integrate chronic illness and public health content in the course. The questions that were developed to guide learning and be answered by the learner showed the abilities of the participants to think through processes they used to problem solve issues. Furthermore, the approach allowed them to be creative in the development of the story as a basis for learning.

Participants presented various levels of problem solving skills and critical thinking as they completed the course. The assignment allowed each participant to build on current problem solving and clinical decision making skills. Some indicated that there was too much emphasis on public health and not enough on chronic illness, suggesting that they were challenged in integrating and applying knowledge in developing the case study. Others had difficulty in building and applying the knowledge, as evidenced by their comments that the assignment required them to do what instructors "should do". They wanted to know the "right answers" without considering aspects needed to resolve the clinical problems. The varying responses from participants indicated a wide range of learning and abilities in problem solving. In addition to providing opportunities for participants to expand their abilities, this learning strategy provided faculty with data for formative and summative evaluation of how students construct meaning through completing this activity. The findings from this survey are consistent with a previous study of RN-BSN students ${ }^{[1]}$. In both, participants demonstrated information gathering abilities, but experienced more difficulty in constructing meaning from the information. 


\section{Recommendations and conclusions}

The use of unfolding case studies is an innovative problem-based learning method that can facilitate critical thinking skills and problem solving for nursing students in an online environment. As demonstrated in this project, it connected current student knowledge with new learning, provided a bridge for translation into practice, and provided a structure for increasing problem solving skills. The unfolding case study provided a venue through which each participant could be evaluated based on their current level of practice and increase skills through the case study development.

The limitations identified in this assignment provide a basis for future recommendations of this problem based learning method. Increasing structure and guidelines for completing each stage would provide guidance for participants as they incrementally and individually learn the process involved in problem solving. Further integration of chronic illness with public health could be accomplished through the use of the chronic care model which addresses self-management through the use of appropriate community and healthcare system resources ${ }^{[11]}$, consistent with the approaches utilized in this assignment.

Expanding self-reflection through exploring what, how, and why of participant thoughts, perceptions and feelings and actions would facilitate participant learning and knowledge transformation ${ }^{[15]}$. By using reflection to analyze situations, participants gain an understanding of their own involvement, and draw lessons for future practice and performance ${ }^{[3]}$. The use of reflection in the context of the unfolding case study could provide opportunity for participants to further articulate and share their understanding of practice. Furthermore, it would provide the structure for discussion and analysis of moral and ethical issues and would facilitate active engagement of participants, encouraging a sense of community and connection with peers and with faculty ${ }^{[2]}$.

The fact that all class participants did not complete the survey limits the ability to interpret the findings. Establishing a structure that encourages feedback and expanding the survey questions to include interviews to explore in greater depth the problem solving experiences of students would increase the trustworthiness of the findings. Finally, while the use of unfolding case studies have been identified as tools for increasing the interface between knowledge and application ${ }^{[16]}$, further exploration of problem solving and clinical decision making experiences in problem based learning are needed ${ }^{[7]}$.

The "unfolding case study" in this public health nursing course served as a means of increasing nurses' knowledge, complex critical thinking and problem solving skills in an online program for RN-BSN students. The structure of the assignment provided opportunity for participants to independently integrate and apply knowledge of chronic illness and solve problems over time. It allowed them to build on their current level of cognitive understanding and expand knowledge of a chronic illness and planning for community based care. Students demonstrated their learning through successful completion of the unfolding case studies and acknowledged the broadening of their perceptions as professionals. "Unfolding case studies", as a problem based method in online learning, can effectively emulate clinical practice and improve creativity and critical thinking skills that are necessary for clinical decision making. Consistent with research

findings ${ }^{[1]}$, this project demonstrated that the use of unfolding case studies provides the opportunity for participants to increase their level of awareness and understanding that will facilitate safer and more competent practice ${ }^{[7]}$.

\section{Acknowledgements}

The author wishes to acknowledge the assistance of Dr. Janice Hayes in preparation of this manuscript.

\section{References}

[1] Oldenburg NL, Hung WC. Problem-solving strategies used by RN-BSN students in an on-line problem based learning course. J Nurs Educ. 2008; 49: 219-222. PMid:20415329 http://dx.doi.org/10.3928/01484834-20091118-01

[2] Gartland M, Field T. Case method learning: online exploration and collaboration for muliticultural learning. Multicultural Perspect. 2004; 6: 30-35. http://dx.doi.org/10.1207/S15327892mcp0601_6 
[3] Price B. Self-assessment and reflection in nursing education. Nurs Standard. 2005; 19: 33-37. PMid:15819331

[4] Smith GG, Passmore D, Faught T. The challenges of online nursing education. Internt Higher Educ. 2009; 12 : 98-103. http://dx.doi.org/10.1016/j.iheduc.2009.06.007

[5] Woodhouse J. Strategies for healthcare education: how to teach in the 21st century. London: Radcliffe, 2005.

[6] Azzarello J, Wood DE. Assessing dynamic mental models: unfolding case studies. Nurs Educ. 2006; 31:10-14. http://dx.doi.org/10.1097/00006223-200601000-00004

[7] Reece CE. Unfolding case studies. J Cont Educ Nurs. 2011; 42: 344-345. PMid:21800789 http://dx.doi.org/10.3928/00220124-20110722-04

[8] Hodges LC, Stanton K. Translating student comments on evaluation into the language of learning. Innovations Higher Educ. 2007; 31: 279-286. http://dx.doi.org/10.1007/s10755-006-9027-3

[9] Kim S, Phillips WR, Pinksy L, Brock D, Phillips K, Keary J. A conceptual framework for developing teaching cases: a review and synthesis of the literature across disciplines. Med Educ. 2006; 40: 867-876. http://dx.doi.org/10.1111/j.1365-2929.2006.02544.x

[10] Glendon K, Ulrich DL. Unfolding case studies: an experiential learning model. Nurs Educ. 1997; 22: 15-18. http://dx.doi.org/10.1097/00006223-199707000-00009

[11] Lubkin IM, Larsen P. (eds). Chronic illness: impact and interventions. Boston: Jones and Bartlett, 2009. PMid:18926832

[12] Allender JA, Rector C, Warner KD. Community health nursing: promoting and protecting the public's health. (7th ed.). Philadelphia: Lippincott, Williams \& Wilkins, 2010.

[13] Flyvbjerg B. Five misunderstandings about case-study research. Qual Inquir. 2006; 12: 219-245. http://dx.doi.org/10.1177/1077800405284363

[14] American Association of Colleges of Nursing. The essentials of baccalaureate education for nursing practice [Internet]. 2008. Available from: http://www.aacn.nche.edu/publications/0rder-form/baccalaureate-essentials.org.

[15] Lethbridge K, Andrusyszyn MA, Iwasiw C, Laschinger H, Fernando R. Structural and psychological empowerment and reflective thinking: is there a link? J Nurs Educ. 2011; 50: 636-645. PMid:21846073 http://dx.doi.org/10.3928/01484834-20110817-02

[16] Lunney M. Current knowledge related to intelligence and thinking with implications for the development and use of case studies. Int J Nurs Terminologies and Classifications. 2008; 19: 158-159. PMid:19128334

http://dx.doi.org/10.1111/j.1744-618X.2008.00104.x 